\section{Local anaesthesia through the action of cocaine, the oral mucosa and the Vienna group}

\author{
A. López-Valverde, ${ }^{* 1}$ J. de Vicente, ${ }^{1}$ L. Martínez-Domínguez ${ }^{2}$ \\ and R. Gómez de Diego'
}

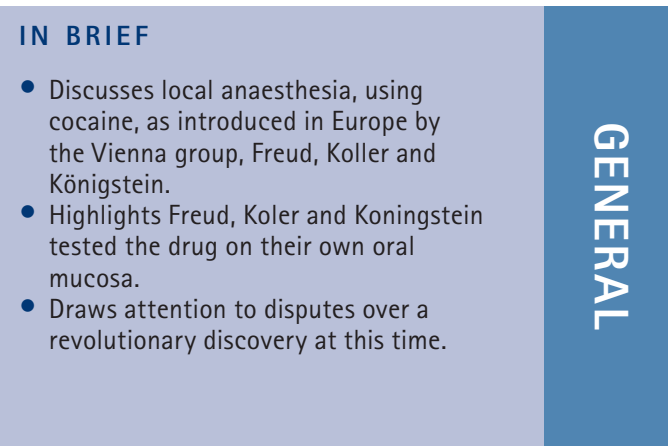

Local anaesthesia through the action of cocaine was introduced in Europe by the Vienna group, which includeed Freud, Koller and Königstein. Before using the alkaloid in animal or human experimentation all these scientists tested it on their oral mucosa - so-called self-experimentation. Some of them with different pathologies (that is, in the case of Freud), eventually became addicted to the alkaloid. Here we attempt to describe the people forming the so-called 'Vienna group', their social milieu, their experiences and internal disputes within the setting of a revolutionary discovery of the times.

\section{INTRODUCTION}

In the last decade of the nineteenth century, the Medical Surgical School in Vienna was very famous and hosted elite scientists such as Moriz Kaposi, Theodoure Billroth, Ernst Ludwig, Solomn Stricker and Friedrich Shauta, among others. Their ideas were continually debated and contrasted in public and this led to several scientific discoveries and helped the Vienna School become one of most important of its times. Indeed, it was an obligatory destination for physicians worldwide, who travelled to the old continent in search of knowledge and perfection. ${ }^{1}$

\section{The Vienna group}

Sigismund Schlomo Freud (Fig. 1) began his medical studies at the University of Vienna in 1874. As a student he had worked at the Ritter Institute of Physiology, where, together with Ludwig, Ritter had revolutionised physiology a quarter of a century before.

Whilst there, Freud developed a warm friendship with Ernst von FleischlMarxow, the discoverer of the electrical activity of the brain, thus predating the electroencephalogram. In 1884, after passing through Billroth's Surgery Service, the Internal Medicine Service with Nothnagel and Meynert's Psychiatric Clinic, Freud

'Associate Professor, School of Dentistry, Faculty of Medicine, Department of Surgery, University of Salamanca, Campus Miguel de Unamuno, Salamanca 37,007, Spain; ${ }^{2}$ Collaborating Centre for Research and Development CES-Vitaldent, Madrid, Spain. ${ }^{*}$ Correspondence to: Dr. Antonio López-Valverde Email:anlopezvalverde@gmail.com

\section{Refereed Paper}

Accepted 17 April 2014

DOI: 10.1038/sj.bdj.2014.546

${ }^{\circledR}$ British Dental Journal 2014; 217: 41-43

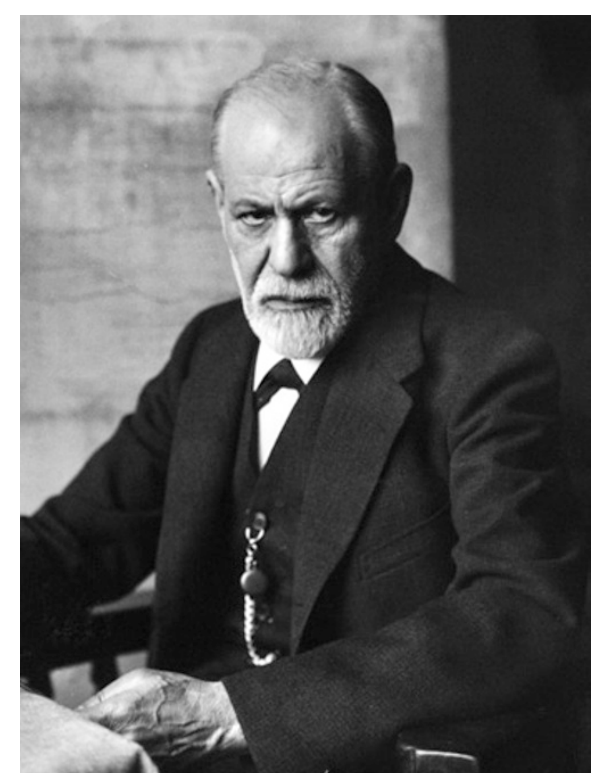

Fig. 1 Sigmund Freud. Source: Historic Print, public domain

began a visit - under the supervision of Franz Scholz - to the Department of Neurological Diseases. This opportunity allowed him to publish his work on cocaine between 1884 and $1886 .^{2}$

Carl Koller (Fig. 2) was also a pupil in 1884. He lived on the same floor as Freud in the hospital and they would meet on a daily basis and often share their aspirations and interests. In 1875 he spent a year studying law at the University of Vienna, but changed to medical studies the following year. ${ }^{3}$

Koller was a pupil of Ferdinand von Arlt, who in his lectures used to comment on the disadvantages of general anaesthesia for eye surgery, among them the nausea and vomiting and the difficulty involved in immobilising the eyeball during surgery. For this type

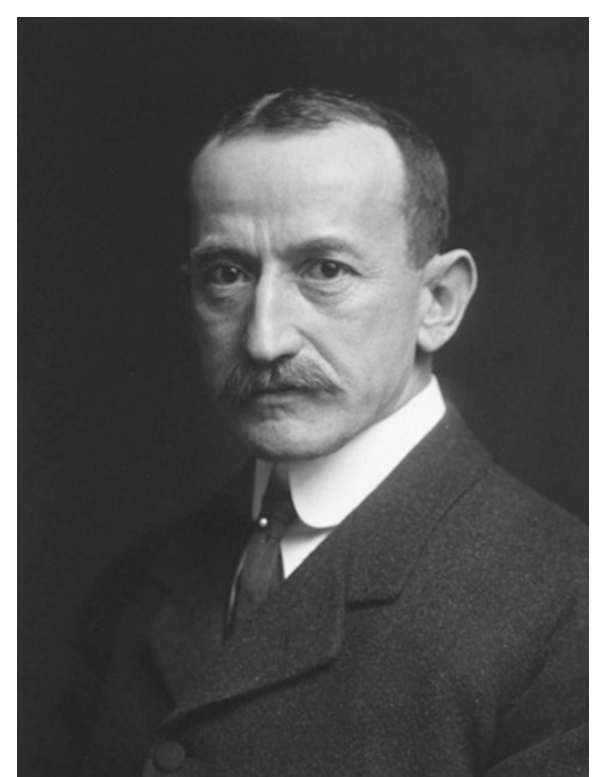

Fig. 2 Carl Koller. Source: US National Library of Medicine, History of Medicine Division

of surgery, he stressed, a local anaesthetic was needed. Koller had searched for a local anaesthetic to immobilise the eye and had tested ether, ethyl chloride, chloral hydrate, bromide, morphine and other substances. ${ }^{4}$

Much less well known is the work of Leopold Königstein (Fig. 3), who at the time was an assistant professor of Ophthalmology at the University of Vienna. He began to study medicine in 1873 and was designated docent in 1881. Accordingly, he was more experienced and held a higher position than Freud or Koller. ${ }^{5}$

\section{From erythroxylum to cocaine}

The only two general anaesthetics available in those days were ether and chloroform, the latter from Duncan Flockkart \& Co, used 


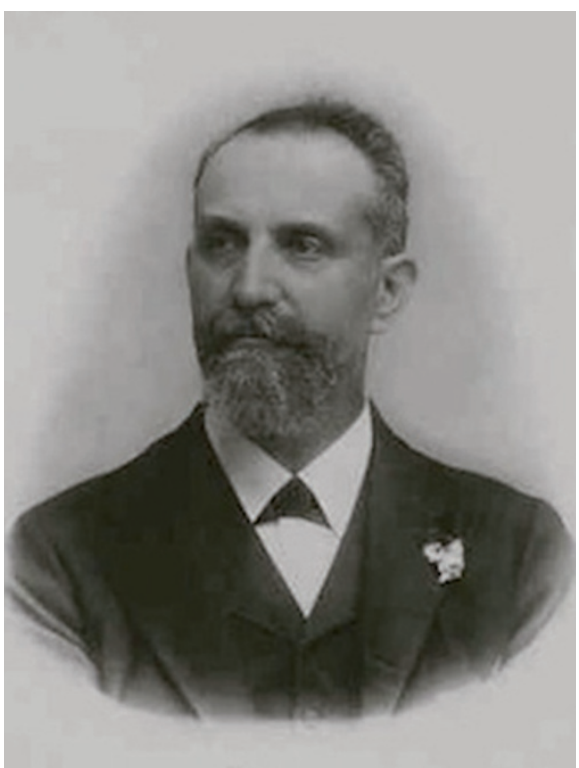

Fig. 3 Leopold Königstein. Source: The European Library

since 1847 by Dr Simpson in obstetrics and some interventions involving minor surgery.

Before the advent of electric lighting, burners or candles were used and their flames decomposed chloroform, generating gases that intoxicated patients, physicians and assistants and even caused explosions in surgical settings.

All these dangers, together with the fact that the substances tended to be administered by people without the proper medical training, meant that it was crucial to find an anaesthetic for local use in minor interventions.

Around 1865, the Austrian chemist Wilhelm Clemens Lossen discovered the formula of cocaine. The drug achieved a certain scientific and social prestige, leading to its use in some diseases. One of its first uses was precisely as a local anaesthetic.

In 1855, a German chemist, Fiedrich Gaedcke, had isolated red crystals from the coca leaf and had called the substance 'erythroxylum', reporting its ability to anaesthetise the tongue. ${ }^{6}$ Two years later, Samuel Percy in Ney York made a similar observation and suggested that the substance could have anaesthetic properties. ${ }^{7}$ In 1859 , using alcohol, sulphuric acid, sodium bicarbonate and ether, another German chemist, Albert Niemann, purified Gaedcke's alkaloid and isolated his own alkaloid, cocaine, directly from the leaf. ${ }^{8}$

\section{Anaesthesia of the oral mucosa}

In 1868 Tomás de Moreno y Maiz, a surgeon in the Peruvian army, suggested the use of cocaine as a local anaesthetic. ${ }^{9}$ Ten years later, the French laryngologist Claude Favel reported the use of coca extract as an anaesthetic for the larynx when examining

\begin{tabular}{|c|c|c|c|}
\hline Author & Year & Nationality & Contribution \\
\hline Tomás de Moreno y Maiz & 1868 & Peruvian & $\begin{array}{l}\text { Begins to communicate the use of cocaine as a local } \\
\text { anaesthetic }\end{array}$ \\
\hline Claude Favel & 1878 & French & $\begin{array}{l}\text { Informed about the use of cocaine as a laryngeal } \\
\text { anaesthetic }\end{array}$ \\
\hline Sigmund Freud & 1884 & Austrian & $\begin{array}{l}\text { In Über Coca, he indicated the anaesthetic effect on } \\
\text { the mucosa. }\end{array}$ \\
\hline Friedrich Gaedcke & 1885 & German & Reported the numbing effect of the lingual mucosa \\
\hline Carl Koller & 1885 & Austrian & $\begin{array}{l}\text { Presented cocaine as a local anaesthetic at the } \\
\text { Ophthalmology Congress in Heidelberg }\end{array}$ \\
\hline Samuel Percy & 1887 & American & Indicated its numbing properties \\
\hline
\end{tabular}

and operating on his patients. ${ }^{10}$ The Russian Vasili Von Anrep performed meticulous studies on the effects of cocaine administered to small rodents. He tried it and was the first to go on to inject himself subcutaneously with the substance. He published his results in 1880 and in them he reported the loss of taste and sensitivity of the tongue. ${ }^{11}$

However, it was to be the Vienna group, above all Freud and Koller, who were to discover, with greater precision, the anaesthetic effects of cocaine on the oral and ocular mucosa (Table 1). ${ }^{12}$

\section{DISCUSSION}

Although in 1855 Gaedcke had reported the effects of cocaine on the oral mucosa, Freud - in his work Über Coca - made a complete description of the plant and of its effects in increasing resistance to fatigue and hunger and described the substance as "bitter to the taste and with an anaesthetic effect in the mucous membranes', in addition to describing '...the great capacity of cocaine and its salts to anaesthetise the mucosa when applied in concentrated solution.' He suggested its possible future use as a local anaesthetic. ${ }^{13}$ In February 1923 his friend, the physician Dr Felx Deutch, diagnosed him with a lesion on the right side of his palate, pinpointing it as a squamous cell carcinoma, for which he was operated on 33 occasions. ${ }^{14}$

When Freud's discomfort, which was almost unsuppressable, began, he found refuge in the drug and its anaesthetic effects from 1939, using mouth washes and frequent nasal infiltrations of the aqueous solutions that his maestro Josef Breuer had taught him about; managing to achieve transient anaesthesia of the oral mucosa in his attempt to mitigate the pain. ${ }^{15-17}$

In turn, Koller was aware of the local anaesthetic effect of cocaine and had tested the effects of the alkaloid on his own mouth and tongue. His daughter said that on one occasion Dr Engel shared with her (Koller) some cocaine delivered from the tip of a penknife blade, commenting on how it put his tongue to sleep. She said that that this had been noted by everybody who had tested it. ${ }^{1}$

Although previously there had been speculation about whether cocaine could be used as a local anaesthetic, nobody before Koller had been searching specifically for a drug that might be used as such.

Freud had proposed that Königstein should research the use of cocaine in painful diseases of the eye such as iritis and trachoma. Königstein observed the decrease in discomfort but failed to investigate the cause or draw further conclusions. ${ }^{18}$

On 15 September 1885, Joseph Brettauer, one of Koller's friends, officially presented the discovery of cocaine as a local anaesthetic at the Ophthalmological Congress held in Heidelberg. One of the participants attending the congress, Henry D. Noyes, from the Bellevue Hospital Medical College in New York, sent a letter to the editor of the Journal of Medical Records, which was published on 11 October. In that letter he stated that perhaps the most noteworthy observation during the Congress, concerning a patient from the Heidelberg Ophthalmology Clinic, was a report of the extraordinary anaesthetic potency of a $2 \%$ solution of cocaine hydrochloride when applied to the cornea and the conjunctiva. It seemed that this had been incorporated into ophthalmological practice and was even more important than the discovery of anaesthesia by chloroform or ether in general surgery. ${ }^{19}$

After the Congress at Heildeberg the discovery came to America. The surgeon William S. Halsted of the Johns Hopkins Hospital in Baltimore (USA) learned about the discovery through the 'Noyes Report', although some investigators consider that Halsted and Koller had already been meeting at the University of Vienna between 1878 and 1880 at the Department of Pathology of the Allgemeines Krankenhaus. ${ }^{20}$

A New York surgeon, Richard Hall, was the first to use cocaine as a topical anaesthetic in minor oral surgery. ${ }^{21}$ 
There was no lack of discussion about the discovery among the Vienna group. Koller had personally presented his discovery on 17 October 1884 at the Gesellschaft der Ärtz, the Annual Congress of the Association of Viennese Physicians in a complete, concise and soundly drafted report on the preparation, administration and effect duration of cocaine and even included the appearance of local phenomena brought about by its delivery. In one paragraph he recognised the work of his colleague Freud, saying that: 'studies on cocaine have been possible thanks to the interesting work on therapy by my colleague at the General Hospital, Dr Sigmund Freud.22

At the end of Koller's contribution, Königstein asked for the floor, expounded on his own research and experimentation with cocaine and claimed the discovery for himself, without even mentioning Freud or Koller.

A few days later, Freud spoke about the matter with his friend Julius Wagner-Jauregg (Nobel laureate for medicine in 1927), a docent in neuropathology and a clinician at the department of psychiatry. Both of them interviewed Königstein and demanded that he retract his claim in a letter written to the editor of Medizinische Zeitung in Vienna recognising Koller's authorship. Königstein finally added a paragraph to his article, thus saving his own reputation. ${ }^{18}$ Koller was also asked why he had not mentioned the findings of Von Anrep. He rebutted this, saying that in his work he had clearly cited Von Anrep and added that the only step he had taken was to assign cocaine certain uses of practical usefulness in medicine, in particular in the field of ophthalmology. ${ }^{22}$

In January 1885 Freud's father had to undergo surgery for cataracts. The surgeon was Königstein. Freud helped him and Koller performed the anaesthesia. In his The Interpretation of Dreams Freud recalls that shortly after Koller's discovery his father had had an attack of glaucoma; his friend, Dr Königstein, an ophthalmic surgeon, operated on him while Dr Koller was in charge of the anaesthesia with cocaine. He also commented on the fact that in this case he had managed to gather all three men who had played an important role in the introduction of the use of cocaine as a local anaesthetic. ${ }^{23}$

1. Lesky E. The Vienna Medical School of the 19th century. Baltimore: Johns Hopkins University Press, 1976.

2. Sulloway FJ. Freud, biologist of the mind. Cambridge: Harvard University Press, 1992.

3. Gunther B. Karl Koller: centennial of the discovery of local analgesia. Rev Med Chil 1984; 112: 1181-1185.

4. Wildsmith J A W. Carl Koller (1857-1944) and the introduction of Cocaine into anaesthetic practice. Reg Anesth 1984; 9: 161

5. Wawersik J. History of anaesthesia in Germany. J Clin Anesth 1991; 3: 235-244.
6. Gaedcke F. Ueber das Erythroxylin, dargestellt aus den Blättern des in Südamerika cultivirten Strauches Erythroxylon Coca Lam. Archiv der Pharmazie 1855; 132: 141-150.

7. Machado E. Erythroxylon - new historical and scientific aspects. In Jeri F R (ed) Cocaine. pp 239245. Lima: Pacific Press, 1980.

8. Gootenberg P. Cocaine: global histories. UK: Routledge, 1999.

9. Moreno y Maiz T. Recherches chimiques et physiologiques for l'erythroxylum coca du Perou et la cocaine. Paris: Louis Lecter Libraire Editeur, 1868.

10. Fauvel C. Coca. Gazette des Hôpitaux 1877; 12: 427.

11. Yentis S M, Vlassakov K V. Vassily von Anrep, forgotten pioneer of regional anaesthesia. Anaesthesiology 1999; 90: 890-895.

12. Calatayud J, Gonzales A. History of the development and evolution of local anaesthesia since the coca leaf. Anaesthesiology 2003; 98: 1503-1508.

13. Freud S. 'Über Coca'. Therapie 1884; 2: 289-314.

14. Deutsch F. Reflections on Freud's one hundredth birthday. Psychosom Med 1956; 18: 279-283.

15. Lovell J. Freud, Koller, Halsted and the story of cocaine. Modern Medicine 1993; 5: 91-93.

16. Schur M. The problem of death in Freud's writings and life. Psychoanal 0 1965; 34: 144-147.

17. Wittenberg S M, Cohen L M. Max Schur M.D., 18971969. Am J Psychiatry 2002; 159: 216.

18. Israëls H. El caso Freud. Madrid: Turner, 2002.

19. Noyes H D. The ophthalmological congress in Heidelberg. NYMed Rec 1884; 26: 417-418.

20. López-Valverde A, De Vicente J, Cutando A. The surgeons Halsted and Hall, cocaine and the discovery of dental anaesthesia by nerve blocking. Br Dent J 2011; 211: 485-487.

21. Hall R J. Hydrochlorate of cocaine. NY Med J 1884; 40: 643-644.

22. Koller $\mathrm{C}$. On the use of cocaine for producing anaesthesia on the eye. Lancet 1884; 2: 990-992.

23. Freud S. The Interpretation of Dreams. The MacMillan Company Ed. pp 68. New York, 1913. 